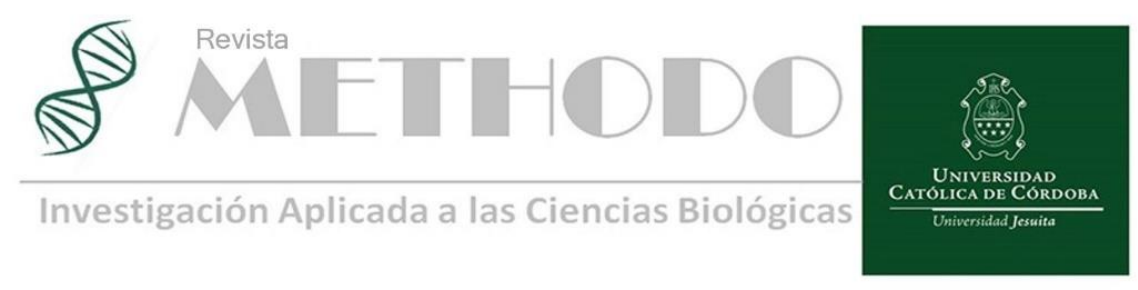

SEMBLANZA Rev. Methodo $2021 ; 6(1): 55-56$

https://doi.org/10.22529/me.2021.6(1)09

Recibido 08 Nov. 2020 | Publicado 05 Ene. 2021

\title{
Prof. Dr. Emilio Noguera (1927 - 2002)
}

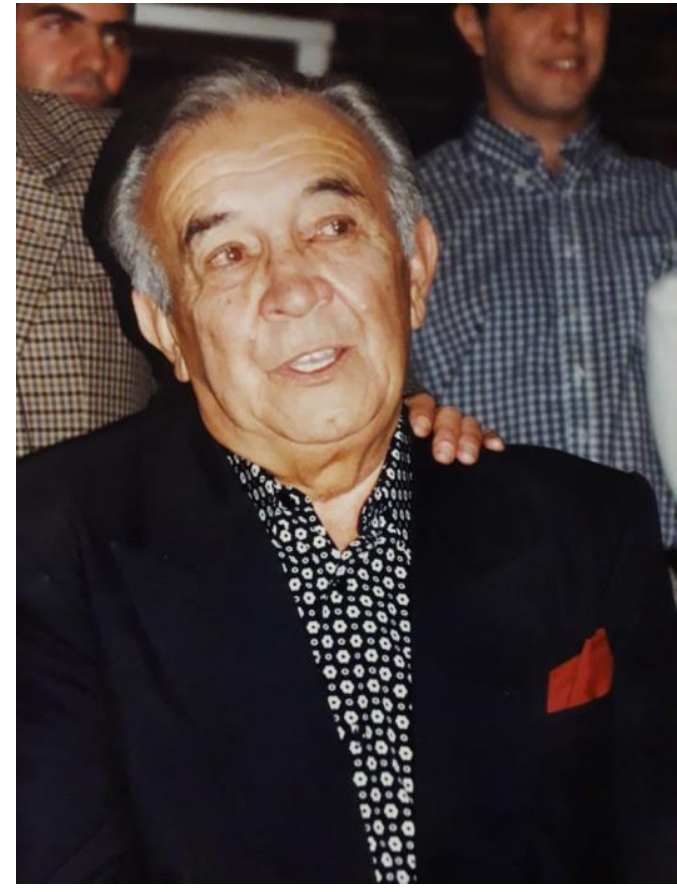

Figura 1. Prof. Dr. Emilio Noguera.

\section{Homenaje al profesor Dr. Emilio Noguera.}

No siempre encontramos las razones de situaciones que nos tocan vivir durante el transcurso de nuestras vidas. Haber conocido y trabajado junto al Dr. Emilio Noguera es una de ellas.
Nació en Concepción de la Sierra, una localidad del interior de la provincia de Misiones, el 3 de mayo de 1927. Cursó sus estudios primarios en su pueblo natal, y se trasladó a Corrientes para realizar los estudios secundarios. A los 19 años vino a Córdoba y comenzó cursar la carrera de médico en la facultad de Medicina de la Universidad Nacional de Córdoba, de donde egresó en 1954. Trabajó en el servicio de Ortopedia y Traumatología del Hospital Córdoba, cuyo jefe era el Dr. Adolfo Fernández Vocos. Este servicio fue en su momento referente en el país.

En 1964 formó su familia; se casó con Gloria del Valle y tuvieron 3 hijos: Sylvia, Gustavo y Emilio. Cuando la clínica Reina Fabiola comenzó sus actividades en Bv. Illia esquina Independencia, él estuvo a cargo del servicio de Ortopedia y Traumatología.

$\mathrm{Su}$ gran pasión fue la docencia y estuvo como Profesor Titular de la Cátedra de Ortopedia y Traumatología de nuestra querida Facultad, luego que el Dr. Ocampo Gari le solicitara hacerse cargo de la misma.

En el año 1973, mientras cursaba quinto año de medicina, lo tuve como Profesor durante el desarrollo lectivo de la materia. Mi inclinación por una especialidad quirúrgica ya estaba en mí, y el excelente desarrollo del curso, me llenó de entusiasmo y no hizo más que confirmar que me incline por esta especialidad.

Después de egresar como Médico, me acerque a él pidiéndole un consejo para formarme a su lado y me sugirió el Servicio del Hospital Córdoba.

Revista Methodo: Investigación Aplicada a las Ciencias Biológicas. Universidad Católica de Córdoba. Jacinto Ríos 571 Bo Gral. Paz. X5004FXS. Córdoba. Argentina. Tel.: (54) 351 4517299 / Correo: methodo@ucc.edu.ar / Web: methodo.ucc.edu.ar | SEMBLANZA Rev. Methodo 2021;6(1):55-56. 
Estuve al lado de los mejores referentes dentro de la especialidad.

En marzo de 1977, me lla mó para trabajar con élen nuestra Clínica, y hasta su jubilación, estuvimos juntos.

Jerarquizó el Servicio de Ortopedia y Traumatología de nuestra Clínica, participando activamente en la creación del quirófano "B" en nuestra institución.

Día a día me deslumbraba con sus conocimientos no solo de Medicina, sino también de cómo enfrentar diferentes situaciones de la vida diaria. Realmente un maestro. Los jóvenes nos arrimábamos permanentemente a él buscando su consejo para conseguir lo más preciado para todos los médicos: aliviar al paciente.

¡iSi habremos tenido charlas de café compartiendo sus conocimientos!! y siempre fue a sí: compartir lo que aprendía en sus pasantías por los mejores servicios de EEUU y Europa. Tuvimos también nuestros roces; una vez me dijo que nuestra relación era como "un noviazgo" en el cual predominaba, por lejos, el disfrutar el trabajo diario con las discrepancias que eran propias. Murió el 26 de febrero de 2002.

Como dije al principio: realmente no sé cuál fue la razón que me llevó a estar bajo su tutela tantos años, pero fue tan grande la impronta que marcó en mi vida que sigue siendo en la actualidad motivo de recuerdos imborrables.

\section{Dr. Jorge Humberto Caruso}

(Universidad Católica de Córdoba. Clínica Universitaria Reina Fabiola Facultad de Ciencias de la Salud).

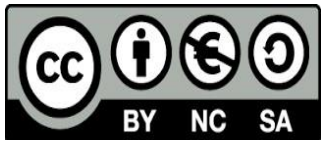

